\title{
Not as black as it is painted? The impact of the first wave of COVID-19 pandemic on surgical treatment of urological cancer patients in Poland - a cross-country experience
}

Piotr Zapała ${ }^{1}$, Aleksander Ślusarczyk ${ }^{1}$, Paweł Rajwa², Mikołaj Przydacz ${ }^{3}$, Wojciech Krajewski Bartosz Dybowski ${ }^{5}$, Przemysław Kubik ${ }^{6}$, Błażej Kuffel ${ }^{6}$, Maciej Przudzik ${ }^{7}$, Rafał Osiecki ${ }^{8}$, Remigiusz Stamirowski ${ }^{9}$, Łukasz Zapała ${ }^{1}$, Mieszko Kozikowski ${ }^{8}$, Dominik Chorągwicki Magdalena Szymańska6, Paweł Kiełb4 ${ }^{4}$, Bartosz Małkiewicz ${ }^{4}$, Jacek Zostawa², Marek Roslan7, Joanna Zajączkowska ${ }^{9}$, Marcin Jarzemski ${ }^{10}$, Bartosz Brzoszczyk ${ }^{10}$, Piotr Petrasz ${ }^{9}$, Piotr Jarzemski ${ }^{10}$, Romuald Zdrojowy ${ }^{4}$, Jakub Dobruch ${ }^{8}$, Andrzej Paradysz², Tomasz Drewa ${ }^{6}$, Piotr Chłosta ${ }^{3}$, Piotr Radziszewski ${ }^{1}$

${ }^{1}$ Department of General, Oncological and Functional Urology, Medical University of Warsaw, Warsaw, Poland

${ }^{2}$ Department of Urology, Medical University of Silesia, Katowice, Poland

${ }^{3}$ Department of Urology, Jagiellonian University Medical College, Krakow, Poland

${ }^{4}$ Department of Urology and Oncologic Urology, Wroclaw Medical University,

Wroclaw, Poland

${ }^{5}$ Department of Urology, Roefler Memorial Hospital, Pruszkow, Poland

${ }^{6}$ Department of General and Oncologic Urology, Antoni Jurasz University Hospital

No. 1, Bydgoszcz, Poland

${ }^{7}$ Department of Urology, Faculty of Medicine, University of Warmia and Mazury,

Olsztyn, Poland

${ }^{8}$ Department of Urology, Centre of Postgraduate Medical Education, Professor

W. Orłowski Independent Public Teaching Hospital, Warsaw, Poland

${ }^{9}$ Department of Urology and Urooncology, Multispecialty Regional Hospital,

Gorzow Wielkopolski, Poland

${ }^{10}$ Department of Urology, Jan Biziel University Hospital, Collegium Medicum

in Bydgoszcz, Nicolaus Copernicus University in Torun, Poland

Submitted: 9 October 2020; Accepted: 27 November 2020

Online publication: 13 January 2023

Arch Med Sci 2023; 19 (1): 107-115

DOI: https://doi.org/10.5114/aoms/130927

Copyright (c) 2020 Termedia \& Banach

\author{
Corresponding author: \\ Aleksander Ślusarczyk MD \\ Department of General, \\ Oncological and \\ Functional Urology \\ Medical University \\ of Warsaw \\ Warsaw, Poland \\ E-mail: slusarczyk. \\ aleksander@gmail.com
}

\begin{abstract}
Introduction: In the majority of Western European countries, the coronavirus disease (COVID-19) pandemic has led to a dramatic reduction in urooncological surgeries. Our objective was to evaluate the impact of the pandemic on volume and patterns of urooncological surgery in Poland.

Material and methods: This is a retrospective analysis of 10 urologic centres in Poland. Data regarding major oncological procedures performed after the COVID-19 pandemic outbreak (March 15, 2020 - May 31, 2020) were evaluated and compared with data from the respective period in 2019.

Results: Between March 15, 2020 and May 31, 2020, a total of 968 oncological procedures were performed in participating centres. When compared to the respective period in 2019 (1063 procedures) the overall number of surgeries declined by $8.9 \%$. The reduction was observed for transurethral resection of bladder tumour (TURBT) (20.1\%) and partial nephrectomies (PN) (16.5\%). Surgical activity considering radical nephrectomy (RN), nephroureterectomy (NU), and radical prostatectomy (RP) remained relatively un-
\end{abstract}


P. Zapała, A. Ślusarczyk, P. Rajwa, M. Przydacz, W. Krajewski, B. Dybowski, P. Kubik, B. Kuffel, M. Przudzik, R. Osiecki, R. Stamirowski, Ł. Zapała, M. Kozikowski, D. Chorągwicki, M. Szymańska, P. Kiełb, B. Małkiewicz, J. Zostawa, M. Roslan, J. Zajączkowska, M. Jarzemski, B. Brzoszczyk, P. Petrasz, P. Jarzemski, R. Zdrojowy, J. Dobruch, A. Paradysz, T. Drewa, P. Chłosta, P. Radziszewski

changed, whereas radical cystectomy (RC) burden showed a significant increase (90.9\%). Characteristics of patients treated with TURBT, RC, NU, PN, and RN did not differ significantly between the compared periods, whereas RP in the COVID-19 period was performed more frequently in patients with a higher grade group $(p=0.028)$ and positive digital rectal examination $(p=0.007)$.

Conclusions: Surgical activity for urological cancers in Poland has been maintained during the first wave of the COVID-19 pandemic. The Polish strategy in the initial period of the COVID-19 crisis mirrors the scenario of hard initial lockdown followed by adaptive lockdown, during which oncological care remained undisrupted and did not require particular priority triage.

Key words: coronavirus, urological cancer, COVID-19, SARS-CoV-2, urooncological surgery.

\section{Introduction}

In late December 2019, an outbreak of unexplained cases of pneumonia was reported in Wuhan, China [1]. After determining the aetiological pathogen as a novel Betacoronavirus and clinical presentation of infection similar to Severe Acute Respiratory Syndrome (SARS), the virus has been officially named SARS-CoV-2 (Severe Acute Respiratory Syndrome Coronavirus 2) [2]. The rapid spread of SARS-CoV-2 reported globally in the preceding weeks led to the coronavirus disease 2019 (COVID-19) being declared a public health emergency of international concern [3]. During February 2020 Europe witnessed a massive outbreak in Italy starting in the Lombardy region. Over the following weeks, rapid pandemic spread was observed, at first in the northern, more polluted provinces [4], reaching eventually a total of 97,869 confirmed cases and 10,779 deaths by the end of March in the whole of Italy [5]. The shift of focus towards critically ill individuals with SARS-CoV-2, presenting commonly as complex cases with comorbidities [6], led to a dramatic shortage of access to urgent urological care [7] as well as a huge drop in planned urological surgeries [8]. The disruption in planned surgeries in Italy caused a $35.9 \%$ decrease in urooncological surgical activity during four consecutive weeks starting from February 24 [8]. In Paris, the relative reduction of urooncological procedures was estimated at $44 \%$ [9]. When considering routine clinical practice, the rapid reorganisation of healthcare led to the increasing prevalence of burnout and physical exhaustion among practising urologists [10]. According to the global survey performed by the UroSoMe group, the COVID-19 outbreak caused a delay of more than 8 weeks in an average of $31 \%$ of surgeries, with personnel shortage (27\%) being the most common reason for cut-down [11]. To maintain access to the most substantial urological services and to limit clinical harm of delays, the Rapid Reaction Group of the European Association of Urology (EAU) introduced guidelines prioritising diagnosis, surgical treatment, and follow-up during the COVID-19 outbreak [12]. Although EAU guidance adapted previ- ous recommendations to the current situation and delivered crucial support to overloaded healthcare, the timing and extent of the implementation of the guidelines in various regions remained unclear. The absolute necessity of implementing priorities has been successfully contested by Martini Klinik [13], where screening and extensive protective measures facilitated maintaining the volume of radical prostatectomy at pre-pandemic levels without compromising epidemiological safety.

At the time of writing, in Poland, since the first confirmed patient, as reported on March 4, 60,281 COVID-19 cases have been detected, including 1938 COVID-19-related deaths (5) (August 21). The spread of COVID-19 in Poland has been classified early by the World Health Organisation as community transmission, but the national healthcare infrastructure was impacted by the pandemic significantly less than in the majority of Western European countries. Although the Polish National Health Fund recommended postponing elective procedures and a significant number of hospitals were transformed into COVID-19 dedicated centres, a vast majority of caregivers have neither experienced imperative indications of urooncological service disruption nor required prioritising triage of oncological patients.

In this multicentre cross-country study, we aim to determine the impact of the first wave of the COVID-19 pandemic on the surgical treatment of urological cancer patients in Poland.

\section{Material and methods}

This nationwide study involved 10 urologic centres in Poland. Data regarding oncological surgeries performed after the outbreak of the first wave of the pandemic in 2020 (March 15, 2020 - May 31, 2020; COVID period) and in the reference period in 2019 (March 15, 2019 - May 31, 2019; pre-COVID period) were retrospectively collected. In all included centres, routine SARS-CoV-2 polymerase chain reaction (PCR) testing was implemented at admission (since April). The analysis included transurethral resection of bladder tumour (TURBT), radical nephrectomy (RN), partial nephrectomy (PN), nephroureterectomy (NU), rad- 
ical cystectomy $(\mathrm{RC})$, and radical prostatectomy (RP). The number of surgeries performed, preoperative patient characteristics that could facilitate prioritising procedures, and perioperative track in the pre-COVID and COVID period were compared. The total decline in surgical activity was measured by dividing the number of procedures performed in the COVID period by the number of procedures performed in the pre-COVID period. If the number of procedures in the COVID period exceeded the number of procedures performed in the pre-COVID period, the calculation was performed inversely to obtain the rate of increase.

\section{Research involving human participants}

All procedures performed during the study were in accordance with the ethical standards of the institutional and national research committee and with the 1964 Helsinki declaration and its later amendments.

\section{Statistical analysis}

Continuous data are shown as mean values supplemented with interquartile ranges (IQR), and categorical data are presented as absolute values and percentages. Data were analysed using non-parametric methods. Differences between median values in compared periods were evaluated using Mann-Whitney $U$ test. Associations between categorical variables were assessed using Fisher's exact test. For all statistical analyses, a two-sided $p$-value $<0.05$ was considered statistically significant. Statistical analyses were performed using SAS 9.4 software.

\section{Results}

Ten urological centres with an availability of 270 beds in 7 out of 16 Polish regions participated in the study (Supplementary Table SI). A total of 1063 and 968 urooncological procedures were reported in the surveyed centres during the preCOVID and COVID periods, respectively. The most common procedure performed was TURBT (626 surgeries in the pre-COVID period and 500 surgeries in the COVID period), followed by RP (190 and 199 surgeries, respectively), RN (91 and 85 surgeries, respectively), PN (97 and 81 surgeries, respectively), RC (44 and 84 surgeries, respectively), and NU (15 and 19 surgeries, respectively).

The overall number of urooncological procedures declined by $8.9 \%$. A two-week interval timetrend comparison between both periods regarding the performed procedures is depicted in Figure 1. The highest reduction was observed in TURBT (20.1\%) and PN (16.5\%). The number of RP and RN remained similar in the COVID period $(4.7 \%$ and $6.6 \%$ change, respectively), whereas the num- ber of RC and NU increased by $90.9 \%$ and $26.7 \%$, respectively.

Preoperative characteristics and length of hospitalisation ( $\mathrm{LOH}$ ) of evaluated cohorts are presented in Table I (surgeries for urothelial cancer), Table II (surgeries for renal cell cancer), and Table III (radical prostatectomy).

\section{Discussion}

This is the first nationwide analysis of urooncological treatment conducted in a country where early, strict lockdown suppressed the SARS-CoV-2 surge during the first weeks of the pandemic. Although subsequent softening of the restrictions resulted in the increasing burden of COVID-19 cases, Poland avoided overloading of the healthcare system during the first wave of the pandemic.

The evolution of a pandemic in Poland during the first months of the COVID-19 crisis differed substantially from its dramatic spread in Spain (386,054 cases - August 21$)$, France $(271,905$ cases - August 21), or Italy $(257,065$ cases - August 21), where the COVID-19 outbreak forced rapid reorganisation of national health systems [5]. By August 21 a total of 60,281 COVID-19 cases had been detected in Poland, with 1938 related fatalities [5]. Although the Polish government introduced a national lockdown, the shift of personnel and resources in Poland remained limited, and the decline in crucial specialist medical services was less pronounced than in Western Europe. Our multi-institutional collaborative team previously reported a $22.5 \%$ decrease in urgent urologic admissions and an $11.9 \%$ decrease in urologic emergency visits during the COVID-19 pandemic in Poland [14]. Although bothersome, the decrease in emergency cases in Poland remained considerably lower than reported in Italian and Portuguese studies where observed declines exceeded 50\% [7, 15].

In the present study, we report an overall reduction of planned oncological procedures by $8.9 \%$. This modest decline cannot be compared with the healthcare crisis in Italy, where the estimated procedure reduction during the first phase of the pandemic varied from $35.9 \%$ (declared in the multicentre survey) [8] to 67\% (Department of Urology in Bergamo Hospital) [16]. Although reports from Italy can be interpreted as being confounded by the particular harm this country initially experienced, the global survey conducted by the UroSoMe Working Group confirmed that Italian observations are relevant worldwide [11]. Responses of 1004 survey participants (mostly Asia, Europe, North America, and South America) revealed 20-53\% cut-downs on urooncological surgeries depending on the cancer type. The recent EAU survey showed that $82 \%$ of European referral centres declared themsleves to be "much" or "very much" 
P. Zapała, A. Ślusarczyk, P. Rajwa, M. Przydacz, W. Krajewski, B. Dybowski, P. Kubik, B. Kuffel, M. Przudzik, R. Osiecki, R. Stamirowski, Ł. Zapała, M. Kozikowski, D. Chorągwicki, M. Szymańska, P. Kiełb, B. Małkiewicz, J. Zostawa, M. Roslan, J. Zajączkowska, M. Jarzemski, B. Brzoszczyk, P. Petrasz, P. Jarzemski, R. Zdrojowy, J. Dobruch, A. Paradysz, T. Drewa, P. Chłosta, P. Radziszewski
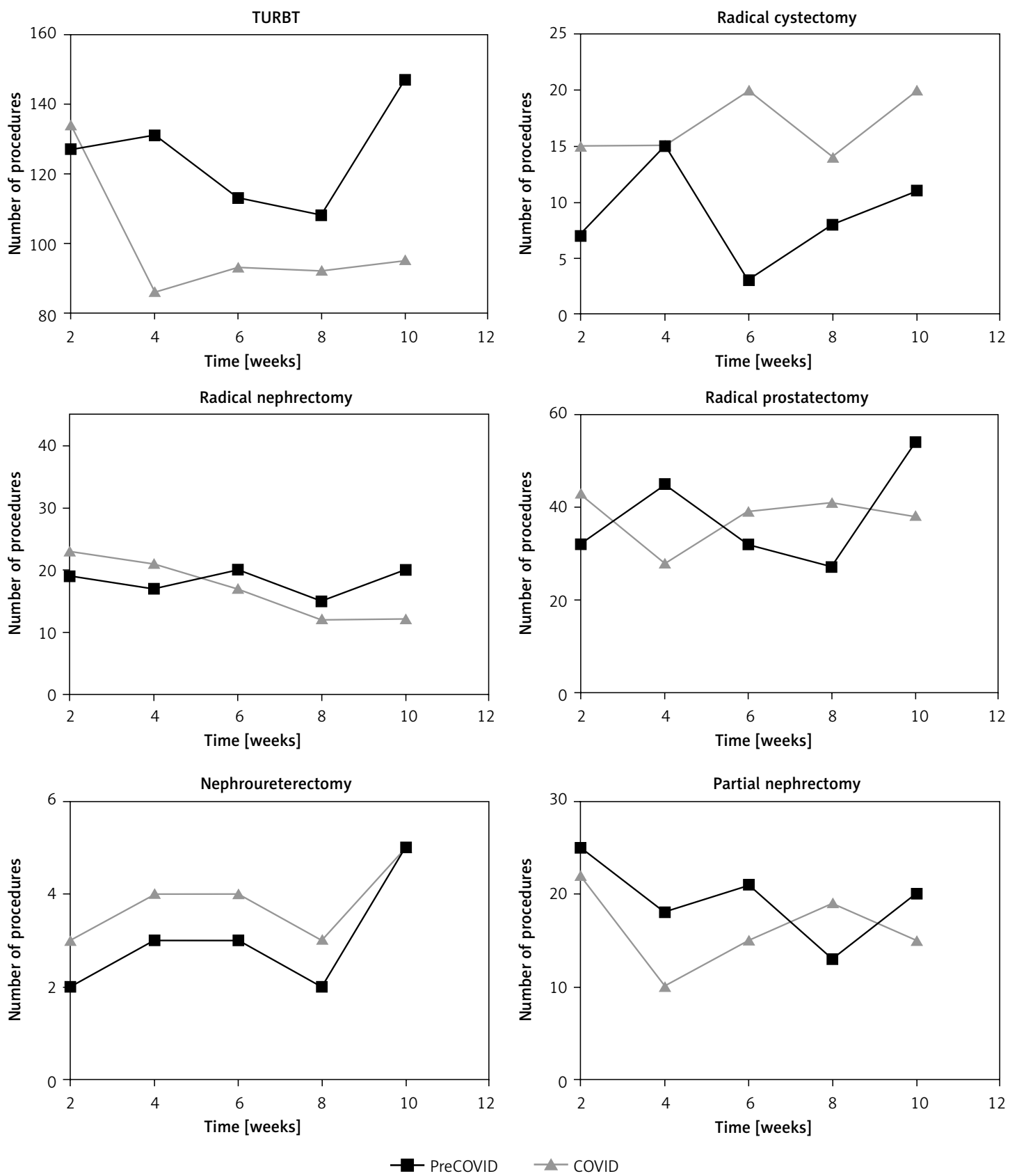

Figure 1. Surgical activity in consecutive weeks* after 15 March, 2020 (COVID) and in the corresponding period in 2019 (pre-COVID). No. - number; TURBT - transurethral resection of bladder tumour; *Time trends are presented for 2-week intervals

affected by COVID-19 pandemic during the first wave (March 2020), reporting 53\%, 41\%, 53\%, and $52 \%$ drops in radical prostatectomies, radical cystectomies, radical/partial nephrectomies, and nephroureterectomies, respectively [17]. Polish observations revealed a different scenario. After stratifying our cohort by procedure, a significant reduction in surgical activity was confirmed only for TURBT (20.1\% decline) and PN (16.5\% decline), with other major procedures being performed without significant decline (RN, RP), or even with an increase (NU, RC).
The substantial decrease in TURBT might be attributed to the limited inflow of patients from outpatients due to disrupted cystoscopy follow-up as well as postponed haematuria investigations. Given the huge drop in outpatient cystoscopy (77\%) after the COVID-19 outbreak revealed in the UroSoMe survey [11], the detection of primary and recurrent urothelial cancer was likely to be altered also in Poland. Considering inpatients, on the other hand, a drop in haematuria cases presenting as urological emergencies could at that moment be as high as $25 \%$ [14]. 
Not as black as it is painted? The impact of the first wave of COVID-19 pandemic on surgical treatment of urological cancer patients in Poland - a cross-country experience

Table I. Characteristics of patients who underwent surgical treatment for urothelial cancer (transurethral resection of bladder tumour, cystectomy, or nephroureterectomy) in pre-COVID and COVID period

\begin{tabular}{|c|c|c|c|c|c|}
\hline Variable & & $\begin{array}{c}\text { Overall } \\
n(\%) / \text { mean } \\
(\mathrm{IQR})\end{array}$ & $\begin{array}{l}\text { Pre-COVID } \\
n(\%) / \text { mean } \\
(\mathrm{IQR})\end{array}$ & $\begin{array}{c}\text { COVID } \\
n(\%) / \text { mean } \\
(\mathrm{IQR})\end{array}$ & $P$-value \\
\hline \multicolumn{6}{|l|}{ TURBT: } \\
\hline Age & & $69.3(14)$ & $69.7(15)$ & $68.9(13)$ & 0.33 \\
\hline Male & & $836(74.2 \%)$ & 459 (73.3\%) & 377 (75.4\%) & 0.45 \\
\hline \multirow[t]{4}{*}{ ASA: } & 1 & $119(10.6 \%)$ & $66(10.5 \%)$ & $53(10.6 \%)$ & 0.91 \\
\hline & 2 & 647 (57.5\%) & $360(57.5 \%)$ & $287(57.5 \%)$ & \\
\hline & 3 & $352(31.3 \%)$ & $195(31.2 \%)$ & $157(31.5 \%)$ & \\
\hline & $\geq 4$ & $7(0.6 \%)$ & $5(0.8 \%)$ & $2(0.4 \%)$ & \\
\hline $\mathrm{Hgb}[\mathrm{g} / \mathrm{dl}]$ & & $13.4(2.3)$ & $13.5(2.2)$ & $13.3(2.3)$ & 0.22 \\
\hline Primary tumour & & $476(42.3 \%)$ & $266(42.6 \%)$ & $210(42.1 \%)$ & 0.90 \\
\hline HG tumour & & $384(34.4 \%)$ & $214(34.5 \%)$ & $170(34.4 \%)$ & 1 \\
\hline Haematuria & & $344(31 \%)$ & $192(30.7 \%)$ & $152(31.3 \%)$ & 0.84 \\
\hline reTURBT & & 224 (19.9\%) & $116(18.5 \%)$ & $108(21.6 \%)$ & 0.20 \\
\hline $\mathrm{LOH}$ & & $2.8(1)$ & $2.8(1)$ & $2.9(1)$ & 0.56 \\
\hline \multicolumn{6}{|l|}{ Cystectomy: } \\
\hline Age & & $68.8(10)$ & $69.1(9)$ & $68.6(11)$ & 0.90 \\
\hline Male & & $107(83.6 \%)$ & $37(84.1 \%)$ & $70(83.3 \%)$ & 1 \\
\hline \multirow[t]{3}{*}{ ASA: } & 1 & $3(2.3 \%)$ & $0(0 \%)$ & $3(3.6 \%)$ & 0.25 \\
\hline & 2 & $54(42.2 \%)$ & $22(50 \%)$ & $32(38.1 \%)$ & \\
\hline & 3 & $71(55.5 \%)$ & $22(50 \%)$ & $49(58.3 \%)$ & \\
\hline $\mathrm{Hgb}[\mathrm{g} / \mathrm{dl}]$ & & $11.8(3)$ & $12.1(3.2)$ & $11.7(11.8)$ & 0.56 \\
\hline Laparoscopy & & $58(45.3 \%)$ & $20(45.5 \%)$ & $38(45.2 \%)$ & 1 \\
\hline \multirow[t]{2}{*}{ TURBT pathology: } & High-risk NMIBC & $45(35.4 \%)$ & $15(34.1 \%)$ & $30(36.1 \%)$ & 0.93 \\
\hline & MIBC & $79(62.2 \%)$ & $28(63.6 \%)$ & $51(61.5 \%)$ & \\
\hline \multirow[t]{5}{*}{$\mathrm{cN}:$} & NO & $95(74.2 \%)$ & $35(79.6 \%)$ & $60(71.4 \%)$ & 0.21 \\
\hline & N1 & $16(12.5 \%)$ & $5(11.4 \%)$ & $11(13.1 \%)$ & \\
\hline & N2 & $7(5.5 \%)$ & $3(6.8 \%)$ & $4(4.8 \%)$ & \\
\hline & N3 & $2(1.6 \%)$ & $1(2.3 \%)$ & $1(1.2 \%)$ & \\
\hline & $\mathrm{Nx}$ & $8(6.3 \%)$ & $8(9.5 \%)$ & $0(0 \%)$ & \\
\hline \multirow[t]{4}{*}{$\mathrm{cT:}$} & $\leq \mathrm{T} 1$ & $22(17.2 \%)$ & $10(22.7 \%)$ & $12(14.3 \%)$ & 0.41 \\
\hline & $\mathrm{T} 2$ & $51(39.8 \%)$ & $18(40.9 \%)$ & $33(39.3 \%)$ & \\
\hline & T3 & $39(30.5 \%)$ & $13(29.6 \%)$ & $26(31 \%)$ & \\
\hline & T4 & $16(12.5 \%)$ & $3(6.8 \%)$ & $13(15.5 \%)$ & \\
\hline Hydronephrosis & & $43(33.6 \%)$ & $10(22.7 \%)$ & $33(39.3 \%)$ & 0.077 \\
\hline Tumour diameter [mm] & & $38.4(39)$ & $33.2(41)$ & $40.7(40.5)$ & 0.098 \\
\hline Haematuria & & $68(53.1 \%)$ & $21(47.7 \%)$ & $47(60.3 \%)$ & 0.19 \\
\hline $\mathrm{LOH}$ & & $13.8(6)$ & $14(6)$ & $13.6(6)$ & 0.59 \\
\hline \multicolumn{6}{|l|}{ Nephroureterectomy: } \\
\hline Age & & $69.3(9)$ & $68.5(10)$ & $69.9(10)$ & 0.78 \\
\hline Male & & $18(52.9 \%)$ & $9(60 \%)$ & $9(47.4 \%)$ & 0.51 \\
\hline \multirow[t]{3}{*}{ ASA: } & 1 & $1(2.9 \%)$ & 1 (6.7\%) & $0(0 \%)$ & 0.72 \\
\hline & 2 & 17 (50\%) & 7 (46.7\%) & $10(52.6 \%)$ & \\
\hline & 3 & $16(47.1 \%)$ & 7 (46.7\%) & $9(47.4 \%)$ & \\
\hline $\mathrm{Hgb}[\mathrm{g} / \mathrm{dl}]$ & & $12.6(1.5)$ & $13.2(2.9)$ & $12.2(1.5)$ & 0.35 \\
\hline Laparoscopy & & $22(64.7 \%)$ & $10(66.7 \%)$ & $12(63.2 \%)$ & 1 \\
\hline
\end{tabular}


P. Zapała, A. Ślusarczyk, P. Rajwa, M. Przydacz, W. Krajewski, B. Dybowski, P. Kubik, B. Kuffel, M. Przudzik, R. Osiecki, R. Stamirowski, Ł. Zapała, M. Kozikowski, D. Chorągwicki, M. Szymańska, P. Kiełb, B. Małkiewicz, J. Zostawa, M. Roslan, J. Zajączkowska, M. Jarzemski, B. Brzoszczyk, P. Petrasz, P. Jarzemski, R. Zdrojowy, J. Dobruch, A. Paradysz, T. Drewa, P. Chłosta, P. Radziszewski

Table I. Cont.

\begin{tabular}{|c|c|c|c|c|c|}
\hline Variable & & $\begin{array}{c}\text { Overall } \\
n(\%) / \text { mean } \\
\text { (IQR) }\end{array}$ & $\begin{array}{c}\text { Pre-COVID } \\
n(\%) / \text { mean } \\
(I Q R)\end{array}$ & $\begin{array}{c}\text { COVID } \\
n(\%) / \text { mean } \\
(\text { IQR })\end{array}$ & $P$-value \\
\hline Multifocality & & $8(23.5 \%)$ & $4(26.7 \%)$ & $4(21.1 \%)$ & 1 \\
\hline \multirow[t]{3}{*}{ Location: } & Pelvis & $19(57.6 \%)$ & $8(53.3 \%)$ & $11(61.1 \%)$ & 0.85 \\
\hline & Calyx & $1(3 \%)$ & $1(6.7 \%)$ & $0(0 \%)$ & \\
\hline & Ureter & $13(39.4 \%)$ & $6(40 \%)$ & $7(38.9 \%)$ & \\
\hline Tumour diameter [mm] & & $36.2(21)$ & $34.7(16)$ & $37(26.5)$ & 0.82 \\
\hline HG pathology (URS) & & $9(52.9 \%)$ & $5(62.5 \%)$ & $4(44.4 \%)$ & 0.64 \\
\hline Hydronephrosis & & $24(75 \%)$ & $8(61.5 \%)$ & $16(84.2 \%)$ & 0.22 \\
\hline $\mathrm{LOH}$ & & $8.9(4)$ & $9.1(4)$ & $8.7(4)$ & 0.48 \\
\hline
\end{tabular}

ASA - American Society of Anesthesiologists score, Hgb - haemoglobin, HG - high-grade, reTURBT - restaging transurethral resection of bladder tumour, NMIBC - non-muscle-invasive bladder cancer, MIBC - muscle-invasive bladder cancer, $c N-c l i n i c a l$ nodal staging, CT - clinical local staging, URS - ureterorenoscopy, $\mathrm{LOH}$ - length of hospitalisation.

Table II. Characteristics of patients who underwent surgery for renal cell cancer (partial nephrectomy or radical nephrectomy) in pre-COVID and COVID period

\begin{tabular}{|c|c|c|c|c|c|}
\hline Variable & & $\begin{array}{c}\text { Overall } \\
n(\%) / \text { mean (IQR) }\end{array}$ & $\begin{array}{c}\text { Pre-COVID } \\
n(\%) / \text { mean (IQR) }\end{array}$ & $\begin{array}{c}\text { COVID } \\
n(\%) / \text { mean (IQR) }\end{array}$ & $P$-value \\
\hline \multicolumn{6}{|l|}{ Partial nephrectomy: } \\
\hline Age & & $61.5(15)$ & $61.2(15)$ & $61.9(14)$ & 0.70 \\
\hline Male & & $113(63.5 \%)$ & $58(59.8 \%)$ & $55(67.9 \%)$ & 0.28 \\
\hline \multirow[t]{4}{*}{ ASA: } & 1 & $14(7.9 \%)$ & $6(6.2 \%)$ & $8(9.9 \%)$ & 0.30 \\
\hline & 2 & 105 (59\%) & $63(65 \%)$ & $42(51.9 \%)$ & \\
\hline & 3 & $54(30.3 \%)$ & $25(25.8 \%)$ & $29(35.8 \%)$ & \\
\hline & $\geq 4$ & $5(2.8 \%)$ & $3(3.1 \%)$ & $2(2.5 \%)$ & \\
\hline $\mathrm{Hgb}[\mathrm{g} / \mathrm{dl}]$ & & $13.9(20$ & $13.8(1.9)$ & $14.1(1.7)$ & 0.15 \\
\hline Laparoscopy & & 97 (55.4\%) & $53(56.4 \%)$ & $44(54.3 \%)$ & 0.88 \\
\hline Tumour diameter [mm] & & $34.8(18)$ & $33.8(18)$ & $36.1(20)$ & 0.94 \\
\hline Imperative indication & & $27(15.2 \%)$ & $9(9.3 \%)$ & $18(22.2 \%)$ & 0.021 \\
\hline $\mathrm{LOH}$ & & $6.7(3)$ & $6.7(3)$ & $6.6(3)$ & 0.99 \\
\hline \multicolumn{6}{|l|}{ Radical nephrectomy: } \\
\hline Age & & $62.7(14)$ & $63.9(13)$ & $61.3(14)$ & 0.10 \\
\hline Male & & $121(68.8 \%)$ & $62(68.1 \%)$ & $59(69.4 \%)$ & 0.87 \\
\hline \multirow[t]{4}{*}{ ASA: } & 1 & $14(8 \%)$ & $6(6.6 \%)$ & $8(9.4 \%)$ & 0.89 \\
\hline & 2 & $86(48.9 \%)$ & $44(48.4 \%)$ & $42(49.4 \%)$ & \\
\hline & 3 & $71(40.3 \%)$ & $38(41.8 \%)$ & $33(38.8 \%)$ & \\
\hline & $\geq 4$ & $5(2.8 \%)$ & $3(3.3 \%)$ & $2(2.4 \%)$ & \\
\hline $\mathrm{Hgb}[\mathrm{g} / \mathrm{dl}]$ & & $12.8(3.3)$ & $12.7(3.4)$ & $12.8(3.3)$ & 0.83 \\
\hline Laparoscopy & & $69(39.2 \%)$ & $37(41.1 \%)$ & $32(37.7 \%)$ & 0.65 \\
\hline Tumour diameter [mm] & & $69.2(39)$ & $65.5(40)$ & $73.1(40)$ & 0.28 \\
\hline \multirow[t]{4}{*}{ cT: } & $\mathrm{T} 1$ & $81(52.3 \%)$ & $44(53.7 \%)$ & $37(50.7 \%)$ & 0.26 \\
\hline & $\mathrm{T} 2$ & $35(22.6 \%)$ & $18(22 \%)$ & $17(23.3 \%)$ & \\
\hline & $\mathrm{T} 3$ & $28(18.1 \%)$ & $16(19.5 \%)$ & $12(16.4 \%)$ & \\
\hline & $\mathrm{T} 4$ & $9(5.8 \%)$ & $2(2.4 \%)$ & $7(9.6 \%)$ & \\
\hline Cytoreduction & & $30(17 \%)$ & $15(16.5 \%)$ & $15(17.7 \%)$ & 0.84 \\
\hline $\mathrm{LOH}$ & & $6.9(4)$ & $7.3(4)$ & $6.5(3)$ & 0.028 \\
\hline
\end{tabular}

ASA - American Society of Anesthesiologists score, $\mathrm{Hgb}$ - haemoglobin, $\mathrm{LOH}$ - length of hospitalisation, cT - clinical local staging. 
Table III. Characteristics of patients who underwent surgical treatment for prostate cancer (radical prostatectomy) in pre-COVID and COVID period

\begin{tabular}{|c|c|c|c|c|c|}
\hline Variable & & $\begin{array}{c}\text { Overall } \\
n(\%) / \text { mean (IQR) }\end{array}$ & $\begin{array}{c}\text { Pre-COVID } \\
n(\%) / \text { mean (IQR) }\end{array}$ & $\begin{array}{c}\text { COVID } \\
n(\%) / \text { mean (IQR) }\end{array}$ & $P$-value \\
\hline Age & & $65.1(8)$ & $65.3(8)$ & $64.9(8)$ & 0.59 \\
\hline \multirow[t]{4}{*}{ ASA: } & 1 & 35 (9\%) & $20(10.1 \%)$ & $15(7.9 \%)$ & 0.73 \\
\hline & 2 & $284(73 \%)$ & 142 (71.4\%) & 142 (74.7\%) & \\
\hline & 3 & 69 (17.7\%) & 36 (18.1\%) & 33 (17.4\%) & \\
\hline & $\geq 4$ & $1(0.3 \%)$ & $1(0.5 \%)$ & $0(0 \%)$ & \\
\hline $\mathrm{Hgb}[\mathrm{g} / \mathrm{dl}]$ & & $14.5(1.6)$ & $14.6(1.6)$ & $14.5(1.6)$ & 0.76 \\
\hline Laparoscopy & & 307 (78.9\%) & $158(83.2 \%)$ & 149 (74.9\%) & 0.048 \\
\hline eLND & & 201 (48.3\%) & $102(53.7 \%)$ & 99 (49.8\%) & 0.48 \\
\hline PSA [ng/ml] & & $12.3(8.1)$ & $12.2(7)$ & $12.4(9.3)$ & 0.81 \\
\hline \multirow[t]{5}{*}{ Grade group: } & I & $157(41.3 \%)$ & $86(46 \%)$ & $71(36.7 \%)$ & 0.028 \\
\hline & II & $107(28.2 \%)$ & $56(30 \%)$ & $51(26.4 \%)$ & \\
\hline & III & $62(16.3 \%)$ & $24(12.8 \%)$ & $38(19.7 \%)$ & \\
\hline & IV & $43(11.3 \%)$ & $14(7.5 \%)$ & $29(15 \%)$ & \\
\hline & $\mathrm{V}$ & $11(2.9 \%)$ & $7(3.7 \%)$ & $4(2.1 \%)$ & \\
\hline DRE $(+)$ & & $207(54.5 \%)$ & $90(47.4 \%)$ & $117(61.6 \%)$ & 0.007 \\
\hline \multirow[t]{3}{*}{ cT: } & cT1 & $140(36 \%)$ & 77 (40.5\%) & $63(31.2 \%)$ & 0.13 \\
\hline & CT2 & $206(53 \%)$ & $91(47.9 \%)$ & $115(57.8 \%)$ & \\
\hline & $\geq \mathrm{cT3}$ & $43(11.1 \%)$ & $22(11.6 \%)$ & $21(10.6 \%)$ & \\
\hline $\mathrm{LOH}$ & & $5.8(2)$ & $5.7(3)$ & $5.8(3)$ & 0.084 \\
\hline
\end{tabular}

ASA - American Society of Anesthesiologists score, Hgb-haemoglobin, eLND-extended lymph node dissection, PSA - prostate-specific antigen, DRE - digital rectal examination, CT - clinical local staging, $L O H$ - length of hospitalisation.

When compared to the $35 \%$ mean decrease in surgeries for RCC declared by responders of the UroSoMe survey [11] or the $53 \%$ decline reported in the recent EAU survey [17], the $11.7 \%$ reduction observed in our study cannot be considered more than moderate. The relative reduction of PN might be attributed to the higher number of lowest-risk kidney tumours being postponed from surgery or proposed active surveillance, as has been suggested by the rapid reaction EAU working group $[12,18]$.

In Italy, RP and radiotherapy were estimated to decline by $63.6 \%$ and $84.6 \%$, respectively, until the end of March [19]. In Poland the volume of RP performed after the COVID-19 outbreak did not decrease. We also failed to validate the UroSoMe survey outcomes, which revealed mean global cut-down on radical prostatectomy exceeding $50 \%$ [11]. Given that prostate cancer (PC) is the most deferrable among urological cancers, the question on the risk-benefit ratio of RP during the COVID-19 crisis seems valid as never before. According to the EAU recommendations for the COVID-19 pandemic [12, 18], most prostatectomies for organ-confined intermediate - and highrisk PC can be deferred for 3-6 months without harm, whereas patients with low-risk should be offered active surveillance. The high proportion of patients with grade group (GG) I in biopsy (overall $41.3 \%$ ) in our study suggests a significant burden of overtreatment in Poland, which is however observed constitutively in Polish series [20, 21]. Nevertheless, RP was the only oncological procedure that presented differences between corresponding periods that can be attributed to oncological triage. Prostatectomy in the COVID period was significantly more likely to be performed in patients with an abnormal digital rectal examination (DRE) (61.6\% vs. $47.4 \%)$ and/or GG $\geq$ II patients (63.4\% vs. $54 \%$ ). Of note, abnormal DRE has been recently proposed by the Rapid Reaction Group as one of the major triggers to drive decisions on performing biopsy without delay [12] and might contribute to higher biopsy grading, which constitutes another prioritising factor. Although a trend towards prioritising high-risk PC patients can be noticed, oncological triage in Polish centres presents some similarities with the Martini Klinik, where the implementation of precautions facilitated maintaining PC care at baseline level without compromising epidemic safety [13]. Finally, the COVID-19 outbreak brought a remarkable change in utilising a laparoscopic approach in RP (74.9\% vs. $83.2 \%$ in COVID and pre-COVID, respectively), which possibly reflects previous concerns about an increased risk of aerosolisation during desufflation [22, 23].

Surprisingly, NU and RC were performed more frequently in the COVID period than in 2019. For nephroureterectomy remaining uncommon 
P. Zapała, A. Ślusarczyk, P. Rajwa, M. Przydacz, W. Krajewski, B. Dybowski, P. Kubik, B. Kuffel, M. Przudzik, R. Osiecki, R. Stamirowski, Ł. Zapała, M. Kozikowski, D. Chorągwicki, M. Szymańska, P. Kiełb, B. Małkiewicz, J. Zostawa, M. Roslan, J. Zajączkowska, M. Jarzemski, B. Brzoszczyk, P. Petrasz, P. Jarzemski, R. Zdrojowy, J. Dobruch, A. Paradysz, T. Drewa, P. Chłosta, P. Radziszewski

procedure mild increase in the number of surgeries suggests rather maintaining the baseline activity. The noted increase in radical cystectomies $(90.9 \%)$ is a remarkable observation. Given that more than a quarter of muscle-invasive bladder cancer (MIBC) patients fail to be treated within 12 weeks in Poland [24], cystectomy timing seems to contextualise this phenomenon. A considerable load of RC contributes to prolonging oncological waiting lists, whereas this surgery has been recently identified with the highest (36.2\%) burden of high-priority patients [25]. Because the prevalence of the PT1 category in Polish patients presenting with primary non-muscle-invasive bladder cancer (NMIBC) is more common than in the available series ( $49.2 \%$ vs. $39 \%)$, this burden can be even higher in Poland $[26,27]$. We speculate that the Polish National Health Fund recommendation on postponing elective procedures except for oncological treatment might have unloaded waiting lists of RC candidates. Although not statistically significant, the presence of hydronephrosis (39.3\% in the COVID period vs. $22.7 \%$ in the pre-COVID period) and lesion diameter (mean $40.7 \mathrm{~mm}$ vs. $33.2 \mathrm{~mm}$ ) could have been among the main triggers for surgery during the pandemic.

Despite recent advancements in COVID-19 management and vaccine development, still no clear results and future perspectives can be drawn [28]. European urology is forecasted to face a significant workload requiring maintaining prioritising strategies [17, 29]. Epidemic models suggest that regarding the number of casualties and shorter duration of the lockdown, the most efficient approach would be an initially intensive but further adaptive lockdown strategy [30]. According to this model, mortality would increase linearly with time, even after the first year, but would not overtake the mortality of different models (like continuous lockdown or intermittent lockdown) for a long time. In Poland, the initial "hard" lockdown during the first wave allowed for smooth, gradual inflow of COVID-19 patients without significant influence on urooncological services. Nevertheless, the second wave of the pandemic, which is currently sweeping through Europe, is predicted to have a substantially greater impact on urooncology.

In conclusion, in this study, we report the limited impact of the first wave of the COVID-19 pandemic on urooncological care in Poland. Deployment of staff and limited access to resources during the COVID period have not affected the proceeding of surgical treatment in patients with urological cancers. Simultaneously, it seems that during the initial pandemic period, oncological triage has not been required in the majority of centres, or its impact is yet to be observed. At the moment of publishing data from the first wave of the pandemic, the epidemiological situation is evolving rapidly. Because the second wave of the pandemic in Poland has already presented a dramatically different course, alteration of urooncological service seems unavoidable.

The limitations of our study can be attributed to its retrospective design and the limited period of time that was analysed. Observation times might be too short to determine whether recommendations for urologists during the COVID-19 pandemic have been applied and to what extent. The two periods compared are separated by 1 year, which was chosen to avoid particular confounders (season influence), but it could be a source of other ones (time-dependent changes in surgical services).

\section{Acknowledgments}

There was no grant support made available for this research.

\section{Conflict of interest}

The authors declare no conflict of interest.

\section{References}

1. Guan W, Ni Z, Hu Y, et al. Clinical characteristics of coronavirus disease 2019 in China. N Engl J Med 2020; 382: 1708-20.

2. Zhu N, Zhang D, Wang W, et al. A novel coronavirus from patients with pneumonia in China, 2019. N Engl J Med 2020; 382: 727-33.

3. Sohrabi C, Alsafi Z, O'Neill N, et al. World Health Organization declares global emergency: a review of the 2019 novel coronavirus (COVID-19). Int J Surg 2020; 76: 71-6.

4. Bianconi V, Bronzo P, Banach M, Sahebkar A, Mannarino $M$, Pirro $M$. Particulate matter pollution and the COVID-19 outbreak: results from Italian regions and provinces. Arch Med Sci 2020; 16: 985-92.

5. COVID-19 Map [Internet]. Johns Hopkins Coronavirus Resource Center. [cited 2020 Aug 5]. Available from: https://coronavirus.jhu.edu/map.html

6. Papazafiropoulou A, Antonopoulos S. The COVID-19 pandemic and diabetes mellitus. Arch Med Sci Atheroscler Dis 2020; 5: 200-5.

7. Porreca A, Colicchia M, D'Agostino D, et al. Urology in the time of coronavirus: reduced access to urgent and emergent urological care during the coronavirus disease 2019 outbreak in Italy. Urol Int 2020; 104: 631-6.

8. Rocco B, Sighinolfi MC, Sandri M, et al. The dramatic COVID-19 outbreak in italy is responsible of a huge drop in urological surgical activity: a multicenter observational study. BJU Int 2021; 127: 56-63.

9. Pinar U, Anract J, Duquesne I, et al. Impact of the COVID-19 pandemic on surgical activity within academic urological departments in Paris. Progres En Urol J Assoc Francaise Urol Soc Francaise Urol 2020; 30: 439-47.

10. Dimitriu MCT, Pantea-Stoian A, Smaranda AC, et al. Burnout syndrome in Romanian medical residents in time of the COVID-19 pandemic. Med Hypotheses 2020; 144: 109972 
11. Teoh JYC, Ong WLK, Gonzalez-Padilla D, et al. A global survey on the impact of COVID-19 on urological services. Eur Urol 2020; 78: 265-75.

12. Professionals S-O. COVID-19 Recommendations [Internet]. Uroweb. [cited 2020 Aug 6]. Available from: https:// uroweb.org/guideline/covid-19-recommendations/

13. Würnschimmel C, Maurer T, Knipper S, et al. Martini Klinik experience on prostate cancer surgery during the early phase of COVID-19. Bju Int [Internet]. 2020 May 18 [cited 2020 Aug 6]; Available from: https://www.ncbi. nlm.nih.gov/pmc/articles/PMC7276763/

14. Rajwa P, Przydacz M, Krajewski W, et al. Changing patterns of urologic emergency visits and admissions during the COVID-19 pandemic: a retrospective, multicenter, nationwide study. Arch Med Sci 2021; 17: 1262-76.

15. Madanelo M, Ferreira C, Nunes-Carneiro D, et al. The impact of the coronavirus disease 2019 pandemic on the utilisation of emergency urological services. BJU Int 2020; 126: 256-8.

16. Roscigno M, Naspro R, Piccichè A, et al. A Snapshot from the Department of Urology in Bergamo evaluating the timeline of the SARS-CoV-2 outbreak: which patients are we missing? Eur Urol Focus 2020; 6: 1120-3.

17. Oderda M, Roupret M, Marra G, et al. The impact of COVID-19 outbreak on uro-oncological practice across Europe: which burden of activity are we facing ahead? Eur Urol 2020; 78: 124-6.

18. Wallis CJD, Novara G, Marandino L, et al. Risks from deferring treatment for genitourinary cancers: a collaborative review to aid triage and management during the COVID-19 pandemic. Eur Urol 2020; 78: 29-42.

19. Sciarra A, Salciccia S, Maggi M, et al. Elective procedures for prostate cancer in the time of Covid-19: a multidisciplinary team experience. Prostate Cancer Prostatic Dis 2020; 23: 407-9.

20. Zapała P, Dybowski B, Bres-Niewada E, et al. Predicting side-specific prostate cancer extracapsular extension: a simple decision rule of PSA, biopsy, and MRI parameters. Int Urol Nephrol 2019; 51: 1545-52.

21. Kozikowski M, Powroźnik J, Malewski W, et al. 3.0-T multiparametric magnetic resonance imaging modifies the template of endoscopic, conventional radical prostatectomy in all cancer risk categories. Arch Med Sci 2018; 14: 1387-93.

22. SAGES and EAES Recommendations Regarding Surgical Response to COVID-19 Crisis [Internet]. SAGES. 2020 [cited 2020 Aug 21]. Available from: https://www.sages. org/recommendations-surgical-response-covid-19/

23. sitecorelesme.martin. Updated Intercollegiate General Surgery Guidance on COVID-19 [Internet]. Royal College of Surgeons. [cited 2020 Aug 21]. Available from: https://www.rcseng.ac.uk/coronavirus/joint-guidancefor-surgeons-v2/

24. Poletajew S, Braticevici B, Brisuda A, et al. Timing of radical cystectomy in Central Europe - multicenter study on factors influencing the time from diagnosis to radical treatment of bladder cancer patients. Cent Eur J Urol 2015; 68: 9-14.

25. Campi R, Amparore D, Capitanio U, et al. Assessing the burden of nondeferrable major uro-oncologic surgery to guide prioritisation strategies during the COVID-19 pandemic: insights from three Italian high-volume referral centres. Eur Urol 2020; 78: 11-5.

26. Poletajew S, Biernacki R, Buraczynski P, et al. Stage of bladder cancer in Central Europe - Polish perspective. Neoplasma 2016; 63: 642-7.
27. Rink M, Furberg $\mathrm{H}$, Zabor EC, et al. Impact of smoking and smoking cessation on oncologic outcomes in primary non-muscle-invasive bladder cancer. Eur Urol 2013; 63: 724-32.

28. Borgio JF, Alsuwat HS, Otaibi WMA, et al. State-of-theart tools unveil potent drug targets amongst clinically approved drugs to inhibit helicase in SARS-CoV-2. Arch Med Sci 2020; 16: 508-18.

29. Amparore D, Campi R, Checcucci E, et al. Forecasting the future of urology practice: a comprehensive review of the recommendations by International and European Associations on priority procedures during the COVID-19 pandemic. Eur Urol Focus 2020; 6: 1032-48.

30. Westerhoff HV, Kolodkin AN. Advice from a systems-biology model of the corona epidemics. NPJ Syst Biol Appl 2020; 6: 18 